\title{
SOBRE O DESENVOLVIMENTO DA ANÁLISE VOLUMÉTRICA E ALGUMAS APLICAÇÕES ATUAIS
}

\author{
Juliana Terra e Adriana Vitorino Rossi* \\ Instituto de Química, Universidade Estadual de Campinas, CP 6154, 13084-971 Campinas - SP
}

Recebido em 28/11/03; aceito em 25/5/04; publicado na web em 9/9/04

\begin{abstract}
ON THE DEVELOPMENT OF TITRIMETRY AND SOME OF ITS CURRENT APPLICATIONS. Classical methods of analysis played a fundamental role in the development of Chemistry and the chemical industry. They have been tools for analytical procedures since the 18th century, remaining useful until today. The technological appeal of the instrumental methods seems to dazzle the incoming generations of chemists who do not recognize the importance of titrimetry. A short description of the development of titrimetry is presented in order to call attention to historical landmarks for teaching and learning activities in Portuguese. A compilation of some current standard analytical methods that employ titrations is presented to illustrate the availability of titrimetry nowadays.
\end{abstract}

Keywords: titrimetry; historical development; current uses.

\section{INTRODUÇÃO}

A Química Analítica é uma área científica que desenvolve e aplica métodos, instrumentos e estratégias para obter informações sobre a composição da matéria no espaço e no tempo. Para isso, dois aspectos estão envolvidos: a identificação das espécies presentes e a determinação das quantidades relativas de cada uma dessas espécies $^{1}$. A análise qualitativa compreende os ensaios que permitem ao químico identificar elementos presentes e, eventualmente, também, seu estado de combinação em uma amostra. Já a análise quantitativa compreende as técnicas e métodos para determinação das quantidades dos componentes na amostra².

A análise quantitativa cumpriu um importante papel no desenvolvimento da Química em aspectos científicos e tecnológicos. Por exemplo, trabalhos de análise quantitativa permitiram estabelecer as massas atômicas dos elementos e conhecer a composição dos mais variados materiais de origem natural. A análise quantitativa representa, junto à indústria, um papel fundamental, já que abrange o exame de matérias-primas, o controle de materiais nas várias fases de produção, a avaliação da qualidade dos produtos, etc. Nos laboratórios, análises quantitativas estão presentes em trabalhos e estudos com matérias-primas, processos tecnológicos, melhoria dos padrões de qualidade dos produtos, etc. ${ }^{3}$.

Titulação é o processo de adição de quantidades discretas de um dos reagentes, geralmente com o auxílio de uma bureta, no meio reacional para quantificar alguma propriedade. Quando se pretende encontrar uma concentração, a titulação é um procedimento analítico e, geralmente, são feitas medidas de volume, caracterizando as titulações volumétricas; mas, em alguns casos, pode-se monitorar a variação gradual de uma outra grandeza, como a massa, caso das titulações gravimétricas, ou a absorção da luz, como nas titulações espectrofotométricas.

Os métodos volumétricos são um grupo de procedimentos quantitativos baseados na determinação da concentração de um constituinte de uma amostra a partir de uma reação, em solução, deste com um reagente de concentração conhecida, acompanhada pela medida de quantidades discretas de solução adicionada. Genericamente, trata-se de determinar a concentração de uma espécie de interesse em uma amostra a partir do volume (ou massa) de uma solução com concen-

*e-mail: adriana@iqm.unicamp.br tração exatamente conhecida (solução padrão) necessária para reagir quantitativamente com esta amostra em solução (solução problema) ${ }^{4,5}$.

A determinação da concentração de uma solução (solução problema) a partir de sua reação quantitativa com uma quantidade conhecida de uma substância que é pura (padrão primário) é chamada de titulação de padronização, ou simplesmente padronização. Neste caso, após ter sua concentração determinada, a solução problema passa a ser uma solução padronizada ${ }^{4,5}$.

A volumetria tem sido usada para a realização de análises quantitativas há mais de 200 anos. Sendo tradicionalmente considerada como um método primário de análise, é muito utilizada para validar outros métodos secundários ${ }^{6}$.

Nos séculos XVIII e XIX, as análises químicas eram realizadas quase exclusivamente por processos gravimétricos e volumétricos. Entretanto, a partir de 1920, a análise quantitativa foi se enriquecendo com a introdução de métodos baseados na medida de propriedades físicas (ópticas, elétricas, térmicas, entre outras) com o uso de instrumentos apropriados, mais complexos que os requeridos pela gravimetria e/ou volumetria. Para diferenciar, esses novos métodos passaram a ser chamados de métodos instrumentais. Em outras palavras, métodos instrumentais seriam aqueles com uso de equipamentos elétricos para medidas. Impropriamente, esta classificação não considera os equipamentos volumétricos, tais como bureta, proveta e pipeta, nem a balança, mesmo eletrônica, como instrumentos. No entanto, esta divisão é amplamente difundida e encontrada na literatura.

Os métodos analíticos instrumentais que surgiram apresentavam vantagens como rapidez, simplicidade, seletividade e sensibilidade; sendo alguns particularmente apropriados para a determinação de baixas concentrações da espécie de interesse $\left(\mu \mathrm{g} \mathrm{L}^{-1} \mathrm{e}\right.$, em alguns casos, até $\left.\mathrm{pg} \mathrm{L}^{-1}\right)^{3}$. Com isso, estes métodos foram ganhando aceitação cada vez maior e passaram a ser introduzidos nos laboratórios de indústrias e centros de pesquisa.

A partir de 1970, os avanços da eletrônica e da computação contribuíram ainda mais para a popularização das técnicas instrumentais, sempre em função das vantagens analíticas observadas. Paralelamente, técnicas clássicas, como a volumetria, continuaram em uso, mas sem um ritmo intenso de pesquisa ou de desenvolvimento de novas propostas, como ocorria com as técnicas instrumentais ${ }^{7}$. Neste contexto, foi surgindo uma dicotomia entre os métodos ditos clássicos e os métodos tidos como instrumentais.

Em português, as análises volumétricas são nomeadas de diversas 
maneiras, como titulação e volumetria ${ }^{8}$, ou apenas titulação ${ }^{2,9,10}$, ou titrimetria $^{11}$, ou volumetria e titulometria ${ }^{3}$. Possivelmente, esta diversidade seja devida às traduções de termos em francês para inglês e alemão ${ }^{12,13}$, podendo também ser entendida em função das etapas do desenvolvimento histórico dos métodos volumétricos de análise, descritas em trabalhos sobre "titrimetry" ou "titrimetric analysis". Volumetria e titulação são os termos mais comuns, embora também apareça em algumas traduções brasileiras o termo titrimetria, que não consta nos dicionários de língua portuguesa consultados ${ }^{14,15}$.

Para tentar entender a origem do termo titulação, é preciso retornar a relatos iniciais que foram originalmente publicados em francês. $\mathrm{O}$ termo "titre" parece ter sido usado pela primeira vez em 1802, no trabalho "Les Administrateurs - Généraux dês Poudres et Salpêtres"16 e estava relacionado ao grau de pureza ou qualidade de amostras de potassas (nome comum de diversos compostos que contém potássio). Atualmente, "titre", em francês, significa a relação entre a massa/volume de uma substância e a massa/volume do solvente ou da solução, indicando uma unidade de concentração que, em português, corresponde ao título ${ }^{17}$. As primeiras citações de "titre" foram traduzidas para outros idiomas como similar a "title" (título) e desta forma propagou-se no século XIX ${ }^{12,18}$. O primeiro registro de uso do termo "titration" ocorreu em 1832, num trabalho de Gay-Lussac sobre um método para a determinação de prata a partir de uma reação com $\mathrm{NaCl}$ padrão em solução ${ }^{19}$. Associações de "title" com "título", a tradução para o português (que também indica uma unidade de concentração) podem ter originado o significado químico da palavra titulação. Vale destacar que, atualmente, em francês, "titrage" é a palavra que designa titulação, com o sentido dos procedimentos de análise química ${ }^{17}$.

\section{HISTÓRICO DA ANÁLISE VOLUMÉTRICA}

A história da análise volumétrica tem interessantes paralelos com o desenvolvimento teórico e experimental da Química e da indústria química.

Investigações iniciais sobre a composição de alguns materiais, como vinagre, foram o impulso para os primeiros procedimentos envolvendo alguns princípios da análise volumétrica ainda sem fundamentação científica para os resultados.

Em épocas anteriores a Dalton, não havia base teórica para fundamentar os princípios da análise volumétrica, mas isso não impediu a disseminação da idéia de que uma dada quantidade de substância $\mathbf{A}$ sempre reagia com uma certa quantidade de substância $\mathbf{B}$. Era uma alusão clara ao princípio da equivalência, que foi aceito como fato natural sem necessidade de ser explicado com fundamentos teó$\operatorname{ricos}^{12}$. Ainda no século XVIII, Jeremias Benjamin Ritcher tentou estabelecer relações de proporção matemática entre as quantidades das várias substâncias envolvidas em uma reação, utilizando pela primeira vez o termo estequiometria ${ }^{7}$. Porém, suas idéias não eram consideradas nos trabalhos sobre volumetria que se desenvolviam.

O desenvolvimento industrial no século XVIII acabou realçando a necessidade de análises rápidas e isso estimulou a criação de novos métodos envolvendo titulações, que passaram a ser essenciais para as indústrias. No período inicial de seu desenvolvimento, a análise volumétrica era principalmente usada na indústria e tinha pouca repercussão no meio científico. Foi necessário o renomado Gay-Lussac usar o método para que outros cientistas passassem a se interessar ${ }^{13,20}$.

De acordo com Madsen ${ }^{21}$, o ano de 1729 pode ser considerado como o marco introdutório das titulações. Neste ano, Claude Joseph Geoffroy $^{22}$ apresentou um artigo para a Academia Francesa sobre a determinação de ácido acético no vinagre, a partir da sua reação com carbonato de potássio pulverizado. Segundo este procedimento, o carbonato era adicionado ao vinagre até que não houvesse mais efervescência. Este procedimento talvez não seja uma titulação convencional, mas contém várias etapas características de titulação. Como as massas das quantidades discretas do titulante sólido adicionado eram medidas, esta titulação foi gravimétrica ${ }^{12,18,20}$.

A primeira titulação volumétrica foi publicada em 1756, quando Francis Home descreveu dois métodos, uma titulação ácido-base (de neutralização) e uma titulação de precipitação ${ }^{23}$. No primeiro método, Home propôs a determinação da basicidade de cinzas de plantas a partir de sua reação com ácido nítrico. O ponto final da titulação foi determinado pelo término da efervescência e o "instrumento volumétrico" usado no procedimento descrito foi realmente muito simples: uma colher de chá ${ }^{12,20}$.

Em 1767, Willian Lewis ${ }^{24}$ rejeitou o uso da colher de chá como instrumento de medida e a determinação do ponto final da titulação por efervescência, alegando ser um efeito ambíguo. Ele descreveu o uso de um instrumento para a determinação do volume em "Experiments and observations on american potashes with an easy method of determination of their respective qualities". Neste trabalho, Lewis determinou a qualidade de oito amostras de $\mathrm{KOH}$ comercial, afirmando que "a pureza da soda pode ser estimada a partir de qualquer característica resultante da neutralização de um sal alcalino por um ácido, como, por exemplo, a modificação da cor de um indicador". Então, Lewis sugeriu o uso de extratos de certos vegetais ou de papéis neles embebidos como indicador do fim da titulação.

Lewis foi o primeiro cientista a descrever os princípios fundamentais da titulação: introdução do uso de indicadores visuais, instrumentos de medidas mais precisos e determinação da concentração da espécie de interesse de uma amostra através da reação com um padrão. No entanto, apesar de seus esforços, as descrições de Lewis não foram bem interpretadas por seus contemporâneos e seu nome não foi lembrado como um marco para o desenvolvimento da análise volumétrica. Apesar de não ter recebido o merecido reconhecido, o trabalho de Lewis foi essencial para diversos trabalhos posteriores, como por exemplo, em 1801 por Lampadius ${ }^{25}$ e por Ure ${ }^{26}$, em 1818, além daqueles que permitiram a François Descroizilles ser considerado o inventor da volumetria por muitos historiadores da Química $^{12,20,27,28}$.

$\mathrm{O}$ uso de indicadores de $\mathrm{pH}$ é uma prática antiga, introduzida no século XVII por Robert Boyle ${ }^{29}$ que observou que, em determinados meios, o extrato de plantas, tais como a rosa e a violeta, tornava-se vermelho e, em outros meios, azul ou verde.

Desde a descoberta de Boyle, descrita em 1663, diversos outros indicadores naturais de $\mathrm{pH}$ foram estudados, mas só no final do século XVIII passaram a ser utilizados nas análises volumétricas, como propunha Lewis. Novas fontes naturais de indicadores ainda continuam despertando interesse e vêm sendo estudadas até os dias de hoje com diversos enfoques, incluindo, por exemplo, a exploração de aspectos didáticos ${ }^{30}$.

Nos 15 anos posteriores à publicação de Lewis, muitos químicos usaram volumetria, mas sem a consolidação dos métodos. Geralmente, só serviam para determinar variações de qualidade de produto, o que era totalmente adequado para as necessidades industriais da época. O interesse por análises de águas minerais levou muitos químicos a aplicarem a volumetria em diversas regiões como Suécia, com o trabalho de T. Bergman ${ }^{31}$ e Itália, com V. A. Gioanetti ${ }^{32}$.

Vale destacar que entre 1782 e 1784, o químico francês Louis Bernard Guynton de Morveau publicou três artigos ${ }^{33-35}$ envolvendo métodos volumétricos, nos quais eram usados indicadores obtidos a partir de tornassol, cúrcuma e pau-brasil. Todos os seus métodos envolviam reações de precipitação, inclusive uma proposta para determinação de cloreto usando nitrato de chumbo. Ele mencionou a possibilidade de usar o nitrato de prata, mas preferiu usar chumbo por razões econômicas. Pela primeira vez a titulação envolveu medidas volumétricas e apareceu a primeira alusão a uma bureta, se a esse 
termo for associada a idéia de um cilindro graduado usado para titulações volumétricas. De Morveau chamou o aparato de "gasometre" $"$.

Pouco avanço ocorreu desta época até o período posterior à Revolução Francesa, quando as dificuldades da França frente ao bloqueio inglês impulsionaram atividades produtivas, inclusive com o financiamento governamental do trabalho de cientistas como GayLussac e François Antoine Henri Descroizilles, que eram empregados do governo ${ }^{13}$.

No final do século XVIII, surgiu um novo tipo de titulação, envolvendo reações de oxidação-redução, a partir dos trabalhos de Descroizilles. Este farmacêutico de formação, mas de atuação eclética, contribuiu de maneira destacada para o desenvolvimento dos métodos volumétricos, mas é um dos nomes esquecidos pela Química, como destacou Clement Duval em $1951^{36}$.

Provavelmente em 1788, Descroizilles acrescentou a titulação de óxido-redução aos já conhecidos métodos de titulação ácido-base e de precipitação. Ele desenvolveu um método para determinar a quantidade de hipoclorito em soluções usadas pelas indústrias têxteis para branquear tecidos. Adicionava-se uma pequena quantidade de ácido sulfúrico diluído e algumas gotas de azul de índigo em um recipiente graduado. Em seguida, lentamente, adicionava-se a solução de hipoclorito a ser testada, até que a coloração do meio reacional passasse de azul para verde pálido ${ }^{7,13}$.

Nesta época, Berthollet atuava na indústria têxtil e, provavelmente em 1788, trabalhando com Lavoisier, deve ter testado o método de Descroizilles, do qual tinha conhecimento indireto por suas

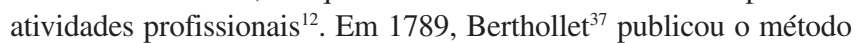
numa seqüência diferente daquela criada por Descroizilles e isso gerava erros que só foram corrigidos quando Descroizilles finalmente publicou seu trabalho em $1795^{38}$. Neste trabalho, aparece a primeira descrição de um tubo de vidro graduado utilizado para a medida de volumes, chamado de "berthollimeter" ${ }^{13}$. Em 1806 39 , este aparato sofreu adaptações e passou a ser chamado de alcalímetro, que Descroizilles usava nos métodos astutamente descritos como "berthollimetry" em suas primeiras publicações sobre titulações volumétricas ${ }^{20,28}$. Interessantes ilustrações das várias versões que antecederam a bureta atual podem ser observadas na obra de Szabadváry "History of Analytical Chemistry"13.

A bureta de Descroizilles funcionava de maneira análoga ao sistema de frascos e pipetas usadas por J. J. Weltr e descritas por Berthollet em $1804^{40}$. Neste trabalho, sobre análise de potassas, havia um procedimento de adicionar o volume de uma pipeta contendo solução de ácido sobre a solução da amostra alcalina. Gotas da mistura resultante eram colocadas em papel de tornassol e o procedimento era concluído quando o papel tornava-se vermelho. O número de pipetadas necessárias para mudar o tornassol de azul para vermelho era dado como o resultado da análise, isto é, se tivessem sido usadas 56 pipetas, o resultado era simplesmente "on dirait que le potasse est au titre 56" ou seja, "o título do mineral foi 56". Esta é mais uma possível explicação para a origem do termo "titration"20.

Alguns estudiosos consideram Descroizilles como sendo o verdadeiro inventor da análise volumétrica. Destaca-se sua contribuição com o desenvolvimento da bureta, que ele mesmo não chamava assim, mas que representou a introdução do senso prático da análise volumétrica com um equipamento multiuso ${ }^{12,36}$. Ele sistematizou a organização de um conjunto de métodos aparentemente diferentes numa categoria distinta, que acabou elevando a volumetria a uma classe de análise quantitativa. O impulso do trabalho de Descroizilles ao desenvolvimento da volumetria é refletido no intenso crescimento de publicações na área nos 50 anos posteriores à publicação de seu trabalho "Notices sur les Alkalis du Commerce", em 1806 39 , a partir do qual a volumetria ficou estabelecida e passou a ser usada por interessados em aplicá-la como conhecimento científico da época.

A última década do século XVIII foi o período de consolidação da acidimetria e alcalimetria. O início do século XIX representou um período importante para a aplicação de novas reações e introduziu o aspecto científico no desenvolvimento da análise volumétrica ${ }^{12,13}$.

Nesta época aparece o outro nome de destaque na volumetria, Joseph Gay-Lussac. Seu trabalho proporcionou uma base sólida para o desenvolvimento da volumetria devido à disseminação do uso de seus métodos, que deixaram de ser aplicações industriais aproximadas e tornaram-se um ramo específico da ciência.

Em 1829, o governo francês, que estava perdendo dinheiro devido a erros na determinação da prata que compunha as moedas, pediu a Gay-Lussac para desenvolver um método simples para a determinação de prata com um erro máximo aceitável de $0,05 \%{ }^{13}$. Neste contexto, em $1832^{19}$, foi publicado seu método mais famoso: a determinação de prata por titulação de precipitação. Questões de ordem econômica estimularam a disseminação do método, que só posteriormente recebeu um nome específico e continua em uso até hoje. Para a realização do experimento, Gay-Lussac utilizou um novo "modelo" de bureta, que representa um estágio intermediário entre o cilindro graduado de Descroizilles e a bureta moderna. Gay-Lussac foi o primeiro a notar a necessidade de correções dos volumes das soluções em função de variações de temperatura e introduziu procedimentos análogos às calibrações ${ }^{13}$.

O primeiro registro de uso de indicador redox em volumetria ${ }^{13}$ ocorreu em 1835, em um trabalho sobre determinação de hipoclorito em cal clorada, com a reação de ácido arsenioso, hexacianoferrato de potássio e nitrato de mercúrio na presença de índigo ${ }^{41}$.

Com relação ao equipamento usado para as titulações, a bureta, vale apresentar um breve resumo. Em $1795^{38}$, Descroizilles descreveu pela primeira vez um cilindro de vidro que seria usado para as titulações, inspirado em Berthollet ${ }^{40}$ que, por sua vez, em colaboração com Weltr, detalhou em 1804 um sistema para realizar as titulações, com frascos e pipetas. Descroizilles publicou em $1806^{39} \mathrm{o}$ que pode ser considerado o protótipo da bureta, que foi modificado por Gay-Lussac em $1835^{41}$. Em 1846, Étienne Ossian Henry descreveu a primeira bureta de vidro com torneira de cobre para o controle do fluxo do titulante ${ }^{42}$. Como as buretas com torneira de cobre, em geral, eram frágeis e caras, em 1855 Karl Friedrich Mohr introduziu uma pinça no lugar da torneira e isso foi usado por muito tempo ${ }^{43}$.

Sobre a inserção da volumetria em livros de Química Analítica, pode-se dizer que houve objeções de autores consagrados do século XIX, provavelmente por não estarem familiarizados com a técnica e por sua origem não acadêmica, fortemente associada a aplicações industriais, que davam caráter pouco exato ou nobre aos trabalhos. A segunda edição da obra de Rose, "Handbuch der analytichen Chemie" ${ }^{44}$ trouxe, em 1831, uma breve menção a uma titulação de hipoclorito com nitrato de mercúrio II e índigo. Na obra de Fresenius "Anleitung zur quantitativen chemishen Analyse", publicada $1841^{45}$, dois métodos volumétricos foram descritos numa breve discussão sobre alcalimetria e métodos clorométricos, com observações de restrição ao seu uso e recomendação para usar balança para as medidas.

O primeiro livro sobre volumetria foi escrito por Karl Heinrich Schwarz e publicado em $1853^{46}$. A obra "Praktishe Anleitung zur Maßanalysen (Titrir-Methode)" foi um livro pequeno, no qual o autor introduziu a palavra "Maßanalyse", inspirado na expressão em francês "dosage à liqueur titrées", que ainda existe em alemão e também é usada em outros idiomas e parece ter sido a origem do termo análise volumétrica. Também parece ter surgido em sua obra a primeira citação da idéia de quantidades equivalentes de substâncias. Schwarz destacou a importância da análise volumétrica para a indústria, aproveitando para contextualizar o enfoque científico da Química Analítica ${ }^{13}$. 
Nesta época, a volumetria ainda não parecia estar definitivamente consolidada no meio científico, que relutava em propalar sua prática. Entretanto, pouco depois da obra de Schwarz, em 1855, surgiu a primeira edição do famoso livro de Mohr "Lehrbuch der chemishanalystichen Titrimethode" ${ }^{43}$, um sólido volume de 750 páginas quase que exclusivamente sobre métodos volumétricos ${ }^{20}$.

Mohr foi outro colaborador destacado para o desenvolvimento da volumetria, além de vários outros aspectos importantes teóricos e experimentais da Química ${ }^{13}$, embora pouco reconhecido. Como exemplo da falta de repercussão de seu trabalho, poucos devem lembrarse que foi ele quem descobriu a lei da conservação da energia ${ }^{13}$. Em Química Analítica, ele introduziu, por exemplo, o uso de cromato de potássio como indicador interno na determinação de cloreto (Método de Mohr), de ácido oxálico como padrão primário para alcalimetria e de sulfato ferroso amoniacal (Sal ou Reagente de Mohr) como padrão para agentes oxidantes ${ }^{43}$.

Mohr sistematicamente usou equações químicas e introduziu a "normalidade" para expressar a concentração das suas soluções padrão, baseando-se na massa equivalente da substância que estaria dissolvida em 1 litro de solução. Esta massa seria relacionada com o peso atômico da substância. Esta forma de expressar a concentração em termos relacionados com o peso atômico pareceu ter sido criada por Mohr neste seu livro. Porém, em publicações posteriores, Mohr indicou que sabia que John Joseph Griffin foi quem, originalmente, introduziu o sistema de peso atômico na volumetria ${ }^{13}$. Seu livro finalmente consolidou a volumetria como um sistema completo de análise e passou a ser usado como obra de referência em Química Analítica por muito tempo. Com várias versões revisadas e ampliadas, a última edição de sua obra ocorreu em 1914. Atualmente, Mohr se faz lembrar em métodos e peças de laboratório que levam seu nome e que ainda estão em uso. Sua obra concluiu um longo período da história inicial da volumetria ${ }^{13}$.

Nas décadas seguintes, foram registrados poucos avanços significativos das análises volumétricas. Os métodos estabelecidos eram aplicados a uma grande variedade de amostras de maneira empírica; quando resultados corretos eram obtidos, o método estava certo.

Nesta época, iniciou-se o interesse pelo comportamento dos indicadores, representando um novo impulso para o desenvolvimento da volumetria no final do século XIX, com a obtenção do primeiro indicador sintético, a fenolftaleína, em $1877^{47}$. Até esta época os indicadores utilizados eram exclusivamente extratos naturais obtidos de plantas. Em 1878, M. Miller sintetizou um novo indicador, a tropeolina ${ }^{48}$, enquanto G. Lunge ${ }^{49}$ sintetizou o alaranjado de metila; em 1893 já havia registro de 14 indicadores sintéticos ${ }^{50}$. Na primeira década do século XX, os cientistas passaram a investigar as propriedades dos indicadores para estabelecer qual indicador seria mais adequado para determinada titulação $0^{13,20,27}$.

A explicação do funcionamento de um indicador de $\mathrm{pH}$ foi dada por Wilhelm Ostwald em 1894 em seu livro "Die wissenschaftliche Grundlagen der analytischen Chemie" ${ }^{51}$. Sua explicação era simples e compreensível. "Para um corante poder ser usado como indicador, é essencial que ele tenha um caráter ácido ou básico e que apresente cores diferentes para as formas não dissociada e iônica. Não deveria ser um ácido forte..." ${ }^{20}$. É importante notar que isto é muito parecido com a definição comum de indicadores de $\mathrm{pH}$ que atualmente se emprega "ácido ou base fraco que apresenta cores diferentes para as formas protonada e desprotonada".

Apesar da explicação de Ostwald, ainda era difícil escolher o melhor indicador para uma determinada titulação. A disponibilidade de novos indicadores sintéticos de $\mathrm{pH}$ tornava a tarefa ainda mais difícil. Um passo para resolver esse problema foi dado por Salm ${ }^{52}$, em 1913, com a determinação das constantes de dissociação de vários indicadores. Neste trabalho, Salm observou que a constante de dissociação do indicador corresponde à concentração de $\mathrm{H}^{+}$, na qual o indicador está $50 \%$ dissociado. Finalmente, passou a ser fácil escolher o indicador adequado para uma determinada titulação.

O primeiro indicador específico para titulações de redox foi introduzido em 1923 por Knop ${ }^{53}$. Daí para frente vários estudos foram realizados por diversos pesquisadores, de tal forma que atualmente encontra-se disponível uma extensa lista de indicadores redox para as mais diversas aplicações ${ }^{13}$.

O terceiro grupo importante de indicadores, os indicadores de adsorção, foi desenvolvido mais recentemente. A fluoresceína foi introduzida por Fajans e Hessel para determinação argentimétrica de cloreto $^{54}$. Uma explicação mais completa sobre o mecanismo desta classe de indicadores foi dada por Schulek e Pungor em $1950^{55}$.

Segundo Beck $\mathrm{II}^{7}$, a primeira titulação condutimétrica foi apresentada em 1903, por Kuster e Gruters, que monitoraram a variação da condutividade elétrica de uma solução em função da adição de pequenos volumes de um reagente, até a quantidade suficiente para estabelecer a reação quantitativa com o outro reagente.

Em 1909, Sörenson ${ }^{56}$ definiu $\mathrm{pH}$ como o logaritmo negativo da concentração dos íons hidrogênio, criando a escala de pH, com números que substituíam a inconveniente representação de valores com expoentes negativos da potência de $10^{19}$. Inspirado no trabalho de Sörenson, em 1913, Hildebrand utilizou o eletrodo de hidrogênio em titulações, introduzindo assim a titulação potenciométrica ${ }^{57}$.

Outro aspecto de interesse envolveu propostas para determinações volumétricas de concentrações mais baixas, com o uso de titulantes diluídos, há muito tempo tentado por Mylius e Förster ${ }^{58}$, e redução de dispositivo de medidas, como fizeram Pilch ${ }^{59}$ e Bang ${ }^{60}$, que apresentou uma microbureta ainda em uso atualmente.

De acordo com Beck II ${ }^{7}$, em 1914, Niels J. Bjerrum publicou um livro descrevendo como obter curvas de titulação e como calcular o erro de titulação na determinação visual do ponto final. Esta pode ser considerada a obra que estabeleceu a teoria "completa" da titulação.

Um dos primeiros trabalhos realizados, utilizando um titulador automático, foi feito por Ziegel ${ }^{61}$ em 1914, no qual uma bureta era controlada por um dispositivo eletromagnético. Em 1948, Lingane ${ }^{62}$ também descreveu um titulador automático, no qual a bureta era controlada por um pistão; este modelo é muito parecido com o que se popularizou até os dias atuais nos laboratório de rotina.

A introdução dos indicadores sintéticos de $\mathrm{pH}$ e dos indicadores redox representaram grande avanço para a volumetria. Szabadváry ${ }^{13}$ considera provável que metade das publicações em Química Analítica de 1900 até 1965 envolveram análise volumétrica.

A titulação iodométrica proposta por Karl Fischer ${ }^{63}$, em 1935, para quantificar água residual em solventes puros, gêneros alimentícios, polímeros e numerosas outras substâncias, foi um grande sucesso que continua em uso, atualmente com detecção iodométrica e eletroquímica de ponto final.

Como resultado de estudos sobre complexos, em 1946 Gerold Schwarzenbach desenvolveu a complexometria, com a descrição de uma titulação de cálcio e magnésio com EDTA $^{64}$ e introduziu a murexida como o primeiro indicador metalocrômico ${ }^{65}$. Os métodos complexométricos tornaram-se muito importantes na indústria, com intenso desenvolvimento de trabalhos envolvendo o EDTA ${ }^{13}$.

Por volta de 1975, surgiram os métodos de análise por injeção em fluxo, FIA (do inglês: "flow injection analysis"), dos trabalhos de Ruzicka e Hansen ${ }^{66}$ na Dinamarca, e do grupo de Stewart ${ }^{67}$ nos Estados Unidos. Logo depois, a volumetria recebeu novo enfoque com a adaptação dos sistemas FIA para trabalhos com titulação, com os trabalhos de Abicht ${ }^{68}$ e do grupo de Toth ${ }^{69}$. Sistemas FIA envolvendo titulação também foram bastante aplicados por pesquisadores brasileiros do Centro de Energia Nuclear na Agricultura da Univer- 
sidade de São Paulo (CENA-USP), como, por exemplo, no trabalho de Korn e colaboradores ${ }^{70}$, que empregaram detecção espectrofotométrica para a determinação do ponto final da titulação em fluxo.

Desde então, com exceção da titulação em fluxo desenvolvida em trabalhos como os de Pasquini e Cunha ${ }^{71,72}$, pouco avanço foi acrescentado à volumetria. Merece destaque a menor titulação realizada por Gratz e Yi em 199373: 29 fmols de $\mathrm{HNO}_{3}$ em uma gota de 1,9 pL de água sob uma camada de heptano em uma placa de Petri, utilizando uma solução de $\mathrm{KOH}$ liberada por difusão da ponta de tubo capilar de $1 \mu \mathrm{m}$ de diâmetro. Uma mistura de indicadores azul de bromotimol e púrpura de bromocresol foi utilizada e o ponto final foi observado por um microscópio acoplado a uma câmera de vídeo ${ }^{73}$.

Atualmente, nota-se que tem havido interesse em estudos para a minimização dos resíduos químicos de volumetria, gerados em laboratório de ensino como, por exemplo, nos trabalhos recentes dos grupos de Micaroni ${ }^{74}$ e Cadore ${ }^{75}$.

\section{ALGUNS USOS OFICIAIS DA ANÁLISE VOLUMÉTRICA}

Os métodos oficiais de análise correspondem a um conjunto de métodos que já foram testados por muitos analistas e são considerados por uma comunidade científica específica os mais adequados para determinadas análises. Ou seja, os métodos oficiais são aqueles que fornecem resultados rápidos, seletivos e específicos (sensíveis). Geralmente eles permanecem em uso até que um novo método que envolva instrumentos mais avançados e/ou forneça resultados mais confiáveis seja estabelecido ${ }^{76}$.

A AOAC ("Association of Official Analytical Chemists") é uma organização internacional reconhecida pelos seus 120 anos de experiência em validar e aprovar métodos para análises de alimentos, medicamentos e produtos agrícolas. Devido a este reconhecimento e por se tratar de uma coleção exclusiva de métodos de análise química, optou-se por se focalizar este levantamento de dados no conteú-

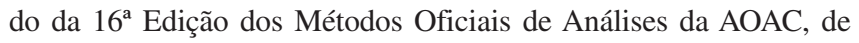
1997, para indicar a aplicabilidade atual da volumetria. Esta edição possui um conjunto de 2036 métodos, sendo que nem todos estão descritos na íntegra; muitos têm como referência os métodos de edições anteriores ${ }^{77}$.

Foram investigados todos os métodos descritos nesta obra que utilizam a volumetria como etapa final e conclusiva das análises. Só foram considerados os métodos com a descrição completa da etapa de determinação ou com indicação, nesta edição, de que a determinação é feita por titulação.

Foram identificados 336 métodos nos quais a quantificação do analito é feita por titulação volumétrica, o que corresponde a $17 \%$ dos métodos.

Estes métodos englobam a quantificação de diversos compostos, íons e elementos, além de índices como de acidez e basicidade, em várias matrizes de alimentos, medicamentos e produtos agrícolas.

Um estudo mais detalhado permitiu verificar que a maior parte (36\%) destes métodos relaciona-se com a determinação de compostos orgânicos. A Figura 1 ilustra uma distribuição dos métodos da AOAC que envolvem titulação na etapa de quantificação, conforme o objeto de determinação da análise volumétrica.

\section{CONCLUSÕES}

Desde o século XVIII, a análise volumétrica tem aplicação intensa e consagrada na indústria, além de outros laboratórios de rotina. Porém, assim como na ocasião de seu surgimento, quando a comunidade científica mostrava reservas quanto ao seu uso por ter surgido de maneira empírica, nos dias de hoje tem surgido certo desin-

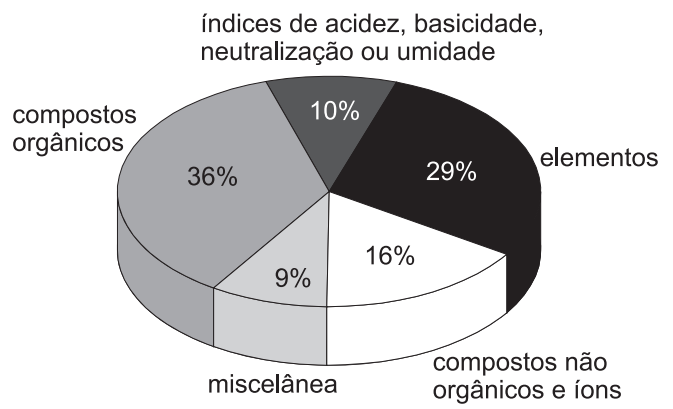

Figura 1. Distribuição das determinações nos 336 métodos analíticos da AOAC que envolvem titulação na fase de quantificação

teresse pela volumetria nas novas gerações de químicos, impressionáveis pelo apelo mais tecnológico dos métodos instrumentais. Assim como muitos conceitos químicos foram consolidados com o desenvolvimento da volumetria, é inegável a relevância dos métodos volumétricos para o aprendizado de Química. Uma breve avaliação de usos correntes da volumetria pode convencer essa geração de estudantes e pesquisadores céticos.

Embora possa haver uma indevida associação das análises volumétricas com métodos ultrapassados ou obsoletos, detectou-se que $17 \%$ dos métodos de análise de uma coleção de referência atu$\mathrm{al}^{77}$ envolvem volumetria, o que deve indicar a sua importância e aplicabilidade nos mais diversos segmentos de análise química.

\section{AGRADECIMENTOS}

As autoras agradecem à CAPES, pelo financiamento do projeto com a bolsa de mestrado de J. Terra.

\section{REFERÊNCIAS}

1. Kellner, R.; Mermet, J. -M.; Otto, M.; Widner, H. M.; Analytical Chemistry: the Authentic Text to the FECS Curriculum, Wiley - VCH: Weinheim, 1998.

2. Harris, D. C.; Análise Química Quantitativa, $5^{\mathrm{a}}$ ed., Livros Técnicos e Científicos Editora S. A.: Rio de Janeiro, 1999.

3. Ohlweiler, O. A.; Química Analítica Quantitativa, $3^{\mathrm{a}}$ ed., Livros Técnicos e Científicos Editora S. A.: Rio de Janeiro, 1982, vol. 1.

4. Skoog, A. D.; West, D. M.; Holler, F. J.; Fundamentals of Analytical Chemistry, $7^{\mathrm{a}}$ ed., Saunders College Publishing: Orlando, 1997.

5. Sandell, E. B.; West, T. S.; Pure Appl. Chem. 1969, 18, 429.

6. King, B.; Metrologia 1997, 34, 77.

7. Beck II, C. M.; Anal. Chem. 1994, 66, 224A.

8. Baccan, N.; Andrade, J. C.; Godinho, O. E. S.; Barone, J. S.; Química Analítica Quantitativa Elementar, $3^{\mathrm{a}}$ ed., Edgard Blücher Ltda: São Paulo, 2001.

9. Guenther, W. B.; Química Quantitativa: Medições e Equilíbrio, Edgard Blücher Ltda: Rio de Janeiro, 1972.

10. Skoog, A. D.; West, D. M.; Holler, F. J.; Princípios de Análise Instrumental, $5^{\mathrm{a}}$ ed., Bookman: Porto Alegre, 2002.

11. Jeffery, G. H.; Bassett, J.; Mendhan, J.; Denney, R. C.; Vogel: Análise Química Quantitativa, $5^{\mathrm{a}}$ ed., Guanabara Koogan S. A.: Rio de Janeiro, 1992.

12. Stephen, W. I.; Anal. Proc. 1980, 17, 73.

13. Szabadváry, F.; History of Analytical Chemistry, Pergamon Press: Oxford, 1966.

14. Houaiss, A.; Villar, M. S.; Franco, F. M. M.; Dicionário Houaiss da Língua Portuguesa, $1^{\text {a }}$ ed., Objetiva: Rio de Janeiro, 2001.

15. Ferreira, A. B. H.; Novo Dicionário Aurélio da Língua Portuguesa, $2^{\mathrm{a}}$ ed., Nova Fronteira: Rio de Janeiro, 1986.

16. Les Administrateurs-Généraux de Poudres et Salpêtres; Ann. Chim. 1802, 11, 113, apud ref.13.

17. Robert, P.; Le Grand Robert de la Langue Française: Dictionnaire de la Langue Française, $10^{\mathrm{a}}$ ed., Le Robert: Paris, 1985.

18. Szabadváry, F.; J. Chem. Educ. 1964, 41, 285.

19. Gay-Lussac, J. L.; Instruction sur l'essay des matiéres d'argent par la voie humide, Paris, 1832, apud ref.13. 
20. Johansson, A.; Anal. Chim. Acta 1988, 206, 97.

21. Madsen, E. R.; The Development of Titrimetric Analysis 'till 1806, C.E.C Gad Publishers: Copenhagen, 1985.

22. Geoffroy, C. J.; Mém. Acad. Roy. Sci. Paris 1729, 68, apud ref. 12.

23. Home, F.; Experiments on Bleaching, Edinburgh, 1756, apud ref. 12.

24. Lewis, W.; Experiments and Observations on American Potashes, London, 1767, apud ref. 12.

25. Lampadius, W. A.; Handbuch zur Chemischen Analyse der Mineralkörper Freyberg, 1801, apud ref. 12.

26. Ure, A.; Dictionary of arts, Manufacture and Mines, First Supplement, London, 1818, apud ref.12.

27. Stephen, W. I.; Analyst 1977, 102, 1220.

28. Bishop, E.; Indicators, Pergamon Press: Oxford, 1972.

29. Boyle, R.; Experiments upon Colors, London, 1663, vol. 2, apud ref. 28.

30. Terci, D. B. L.; Rossi, A. V.; Quim. Nova 2002, 25, 684

31. Bergman, T.; Opuscula Physica et Chemica 1779, 1, 132, apud ref. 13.

32. Gionatti, V. A.; Analyse des eaux minerals de S. Vicent et de Courmayeur dans le Duché avec un appendice sur les eaux de la Saxe, Torino, 1779, apud ref. 13.

33. de Morveau, L. B. G.; Nouv. Mém. Acad. Dijon 1782, II, 1, apud ref. 13

34. de Morveau, L. B. G.; Nouv. Mém. Acad. Dijon 1782, II, 16, apud ref. 13.

35. de Morveau, L. B. G.; Nouv. Mém. Acad. Dijon 1784, I, 85, apud ref. 13.

36. Duval, C.; J. Chem. Educ. 1951, 28, 508.

37. Berthollet, C. L.; Ann. Chim. 1789, 2, 151, apud ref. 12.

38. Descroizilles, F. A. H.; J. Arts Man. 1795, 1, 256, apud ref. 12.

39. Descroizilles, F. A. H.; Ann. Chim. 1806, 60, 17, apud ref. 12.

40. Berthollet, C. L.; Elements de l'art de la teinture. Avec une descriptiom du blanchiment par l'acide muriatique oxigéné, $2^{\mathrm{a}}$ ed., Paris, 1804, apud ref. 13.

41. Gay-Lussac, J. L.; Ann. Chim Phys. 1835, 20, 225, apud ref. 13.

42. Henry, É. O.; Journ. De Chim et Pharm. 1846, 6, 301, apud ref. 13.

43. Mohr, F.; Lehrbuch der chemish-analystichen Titrimethode, Vieweg: Braunschweig, 1855, apud ref. 20.

44. Rose, H.; Handbuch der analytichen Chemie, 1831, apud ref. 13.

45. Fresenius, C. R.; Anleitung zur quantitativen chemishen Analyse, 1841, apud ref. 13.

46. Schwarz, K. H.; Praktishe Anleitung zu Maasanalysen (Titrir-Methode), Braunschweig, 1853, apud ref. 13.

47. Luck E.; Z. Anal. Chem. 1877, 16, 332.

48. Miller, M.; Ber. 1878, 11, 460, apud ref. 13.

49. Lunge, G.; Ber. 1878, 11, 1944, apud ref. 13
50. Trommsdorff, H.; Chem-tech Untersuchungsmethoden. 1893, 11, apud ref. 13.

51. Ostwald, W.; Die wissenschaftliche Grundlagen der analytischen Chemie, 1894, apud ref. 13

52. Salm, E.; Z. Phys. Chem. 1913, 35, 847, apud ref. 20.

53. Knop, J.; Z. An. Chem. 1923, 63, 81, apud ref. 13.

54. Fajans, K.; Hassel, O.; Z. f. Elektrochemie 1923, 29, 495, apud ref. 13.

55. Schulek, E.; Pungor, E.; Anal. Chim.Acta 1950, 4, 213, apud ref. 13.

56. Sörenson, S. P. L.; Biochem. Zeitschrift 1909, 21, 131, apud ref. 13

57. Hildebrand, J. H.; J. Am. Chem. Soc. 1913, 35, 847.

58. Mylius, F.; Förster, F.; Ber. 1891, 24, 1482, apud ref. 13.

59. Pilch, F.; Monatshefte. 1911, 32, 21, apud ref. 13.

60. Bang, J.; Mikrocmethoden zur Blutuntersuchung, München, 1922, apud ref. 13.

61. Ziegel, H.; Trans. Am. Electrochem. Soc. 1914, 26, 91.

62. Lingane, J. J.; Anal. Chem. 1948, 20, 28.

63. Fischer, K.; Z. Angew Chem. 1935, 48, 394, apud ref. 13.

64. Schwarzenbach, G.; Helv. Chim. Acta 1946, 19, 1338, apud ref. 13.

65. Schwarzenbach, G.; Biedermann, W.; Bangerter, F.; Helv. Chim. Acta 1946, 19, 811, apud ref. 13.

66. Rusicka, J.; Hansen, E. H.; Anal. Chim. Acta 1975, 78, 145.

67. Stewart, K. K.; Beecher, G. R.; Hare, P. E.; Anal. Biochem. 1976, 70, 167.

68. Abicht, S. M.; Anal. Chim. Acta 1980, 114, 247.

69. Toth, K.; Nagy, G.; Fether, Z.; Horvai, G.; Pungor, E.; Anal. Chim. Acta 1980, 114, 45.

70. Korn, M.; Gouveia, L. F. B. P; Oliveira, E. ; Reis, B. F; Anal. Chim. Acta 1975, 313, 177.

71. Cunha, I. B. S.; Pasquini, C.; Analyst 1992, 117, 905.

72. Pasquini, C.; Cunha, I. B. S.; Analyst 1995, 120, 2763.

73. Gratzl, M.; Yi, C.; Anal. Chem. 1993, 65, 2085.

74. Micaroni, R. C. C.; Bueno, M. I. M. S.; Jardim, W. F.; Resumos da $23^{a}$ Reunião Anual da Sociedade Brasileira de Química, Poços de Caldas, Brasil, 2000.

75. Cadore, S.; Micaroni, R. C. C.; Bueno, M. I. M. S.; Jardim, W. F.; Resumos da $23^{a}$ Reunião Anual da Sociedade Brasileira de Química, Poços de Caldas, Brasil, 2000

76. The Royal Society of Chemistry; Official and Standardized Methods of Analysis, $3^{\mathrm{a}}$ ed., Ed. Colin Watson: London, 1994.

77. AOAC International; Official Methods of Analysis of AOAC International, $16^{\mathrm{a}}$ ed., AOAC International: Gaithersburg, 1997. 